[0212-7199 (2007) 24: 8; pp 390-392] ANALES DE MEDICINA INTERNA Copyright (C) 2007 ARAN EDICIONES, S.L.

AN. MED. INTERNA (Madrid) Vol. 24, N. ${ }^{\circ} 8$, pp. 390-392, 2007

\title{
Hallazgos radiológicos de la neumonía por virus herpes simple I en el adulto
}

\author{
M. C. CASTILLO-LARIO, J. A. FERNÁNDEZ GÓMEZ, E. JIMÉNEZ-AYLLÓN, \\ E. FREILE GARCÍA, L. VILLAVIEJA-ATANCE
}

Servicio de Radiodiagnóstico. Hospital Clínico Universitario Lozano Blesa. Zaragoza

RADIOGRAPH PATTERNS IN HERPES SIMPLES VIRUS I PNEUMONIA IN THE ADULT

\section{RESUMEN}

El propósito de este estudio es describir epidemiología, patogénesis, manifestaciones pulmonares y hallazgos radiológicos en pacientes adultos con neumonía varicelosa $(\mathrm{NV})$.

Presentamos a 4 pacientes adultos, el diagnóstico de establecido según clínica y radiología. Todos presentaron fiebre y exantema, 3 tos y 2 disnea. La radiología demostró patrón intersticial micronodular basal. 1 caso de sobreinfección por Staphilococcus aureus. 2 ingresaron en UCI. Todos recibieron tratamiento intravenoso con aciclovir.

La NV, suele presentar infiltrados nodulares, siendo generalmente de curso favorable.

PALABRAS CLAVE: Neumonía varicelosa. Adulto. Radiología de tórax. Infiltrados nodulares. Virus zoster.

\section{ABSTRACT}

The aim of this study is to describe epidemiology, patogénesis, pulmonary manifestations and Rx findings in adult patients with varicella pneumonia $(V P)$.

Four patients were studied. The diagnosis was established by clinical and radiologic criteria. All had fever, esanthem, 3 cough, 2 dyspnea.

Chest X-ray showed interstitial micronodular pattern at bases. 1 case developed airspace consolidation by Staphylococcus aureus. 2 were admitted to ICU. The four received IV acyclovir.

We concluyed that adults patients with VP usually show nodular infiltrates, with favourable course.

KEY WORDS: Varicella pneumonia. Adult. Chest radiographs. Nodular infiltrates. Herpes zoster virus.

Castillo-Lario MC, Fernández Gómez JA, Jiménez-Ayllón E, Freile García E, Villavieja-Atance L. Hallazgos radiológicos de la neumonía por virus herpes simple I en el adulto. An Med Interna (Madrid) 2007; 24: 390-392.

\section{INTRODUCCIÓN}

La varicela es una enfermedad infecciosa en la que en adultos y más en inmunodeprimidos, son frecuentes las complicaciones, sobre todo las respiratorias en forma de neumonía varicelosa $(\mathrm{NV})$, que se caracteriza con una buena recuperación clínica, aunque su mejoría radiológica es mas tardía.

\section{CASOS APORTADOS}

Se ha realizado una revisión de las características clínicas y radiológicas de la neumonía como complicación de la varicela en el adulto. Se han valorado los distintos factores de riesgo para la aparición de este cuadro.

Seguimiento de 4 pacientes adultos con sospecha de neumonía varicelosa. A todos los pacientes se les ha valorado sus antecedentes personales, historia de contacto con enfermos con varicela y las manifestaciones de clínica dermatológicas y respiratoria al ingreso. A todos ellos se les han realizado radiografías de tórax al ingresar en el hospital y durante toda su estancia hospitalaria. En uno de ellos fue necesario la realización de una tomografía computarizada de tórax. Se estudiaron los parámetros analíticos más característicos de este cuadro: IgM varicela zoster, hemograma y determinación plaquetaria, gasometría y transaminasas.

Caso 1. Mujer de 36 años sin antecedentes de interés, cuadro catarral, tos, odinofagia y fiebres de $38^{\circ} \mathrm{C}$. Anticuerpos IgM de VZ positivos. Las radiografías mostraban patrón retículo nodular generalizado bilateral. Ingreso de 10 días.

Caso 2. Varón de 34 años, AP: fumador, neumotórax espontáneo a los 20 años. Tos, expectoración mucosa, sibilancias respiratorias en ambos campos, mialgias y fiebre de $39^{\circ} \mathrm{C}$. Radiología: micronódulos en ambos campos pulmonares, con afectación reticulonodular peribroncovascular.

Caso 3. Varón de 38 años, fumador y con antecedentes de asma extrínseca tratada con broncodilatadores esteroideos. Insuficiencia respiratoria, disnea y cianosis. En el estudio radiológico: ocupación 
alveolar bilateral con coalescencia en forma parcheada y difusa (se comprobó posteriormente una sobreinfección bacteriana con Stafilococo Aureus). Ingreso de 6 días en UCI.

Caso 4. Varón 35 años, sin antecedentes, disnea progresiva, taquipnea, fiebre de $40^{\circ}$, hipoventilación y crepitantes basales izquierdos. Radiología simple: patrón intersticial micronodular, con lesiones acinares coalescentes y broncograma de predominio basal.

Todos ellos fueron tratados con Aciclovir IV. La evolución clínica y radiológica en los cuatro casos fue rápidamente favorable, desapareciendo las lesiones en 10 días, incluso en el paciente con sobreinfección bacteriana. Las radiografías en el momento del alta hospitalaria mostraban mínimas alteraciones intersticiales y tres de los pacientes presentaban adenopatías hiliares.

\section{DISCUSIÓN}

La NV es una complicación de la varicela casi exclusiva de los adultos, ya que el $90 \%$ de los casos se presentan en sujetos mayores de 19 años, a pesar de la baja incidencia de varicela en ese grupo de edad (10\% de los casos). Aproximadamente el $10-20 \%$ de adultos con varicela van a desarrollar neumonía (20\% si se incluyen los casos de neumonía sólo radiológica). Está descrita en la literatura una frecuencia de hasta $70 \%$ en el caso de adultos varones. Tanto la varicela como el herpes zoster, pueden dar cuadros de neumonía varicela, pero la frecuencia es mayor en la varicela. La mortalidad oscila desde un 1\%, hasta un $30 \%$ en los casos de evolución a síndrome de distress respiratorio agudo (más frecuente embarazadas e inmunodeprimidos) (1-3).

En cuento a los factores de riesgo para desarrollar una neumonía varicelosa, hay que destacar que rara vez se desarrolla en sujetos previamente sanos, siendo frecuente en pacientes con alteración de la inmunidad celular: VIH, enfermos oncológicos, cánceres hematológicos como leucemias y linfomas, tratamientos corticoideos, inmunosupresores e antibioterapia de amplio espectro. Igualmente la incidencia es mayor en fumadores (como era el caso de nuestro paciente 2) y en embarazo, asociándose en este último caso a alta morbilidad, siendo la neumonía la complicación más frecuente de la varicela en el embarazo $(2,4)$.

La clínica de la NV puede se aguda o subclínica. Los cuadros agudos se manifiestan del primer al sexto día de la aparición de las vesículas, con tos seca o poco productiva, fiebre alta de aproximadamente 7 días de duración, (como en nuestro caso 4), siendo estos síntomas más intensos en fumadores y mayores de 34 años. En los casos más graves puede presentarse tos hemoptóica, cianosis, taquipnea, disnea con cifras bajas de $\mathrm{O}_{2}$, e incluso en el 5-10\% de los pacientes afectación pleural con derrame o lesiones focales. La presentación subclínica sólo se detecta radiológicamente, siendo estos casos los más frecuentes de varicela pulmonar $(5,6)$.

El tratamiento de la varicela suele ser sintomático, evitando AAS en niños para prevenir el síndrome de Reye. Los cuadros mas graves o complicados se tratan con Aciclovir IV (800 mg/5v/d) en asociación con corticoides, siendo menos efectiva la vidarabina. Sólo dar antibioterapia en casos de sobreinfección bacteriana $(5,7)$.

En cuanto a los hallazgos radiológicos, lo más frecuente es una pobre semiología respiratoria con una importante alteración radiológica (Caso 1) (Fig. 1). La afectación suele ser bilateral y extensa, mucho más evidente en hilios y campos superiores pulmonares. El infiltrado intersticial es típicamente

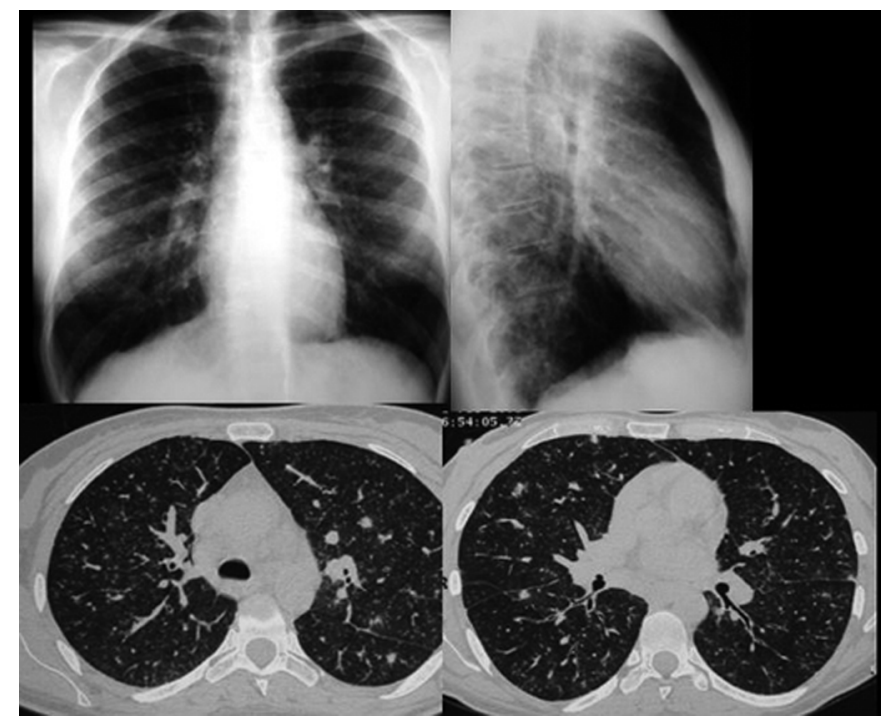

Fig. 1. Caso 1. Estudio radiológico simple PA y lateral de tórax. TC de alta resolución sin contraste I.V. Afectación reticulonodular irregular de forma generalizada en ambos hemitórax. Adenopatías mediastínicas paratraqueales bilaterales y pericarinales.

nodular y difuso, como nuestro paciente 4 , con patrón de neumopatía intersticial y con nódulos de 2 a $20 \mathrm{~mm}$ de diámetro, que pueden coalescer y formar infiltrados extensos que evolucionan a imágenes de consolidación parcheada y difusa del espacio aéreo, manifestada como sombras acinares y condensación alveolar difusa (7-10) (Fig. 2).

La evolución radiológica más frecuente es la desaparición de las imágenes pulmonares en 5-10 días en los cuadros más leves, pero pueden persistir de 6 a 12 semanas en los casos más graves. Se han descrito al respecto tres tipos de evolución clínico radiológica: a) rápidamente regresiva; b) regresión lenta de semanas o meses; y c) progresión hasta la muerte en el $20-50 \%$ de síndrome distrés respiratorio agudo $(4,9,10)$.

Los focos de necrosis focal pueden calcificar dando lugar a un patrón miliar permanente, a veces indistinguible de la tuberculosis, con pequeños nódulos calcificados bilaterales de

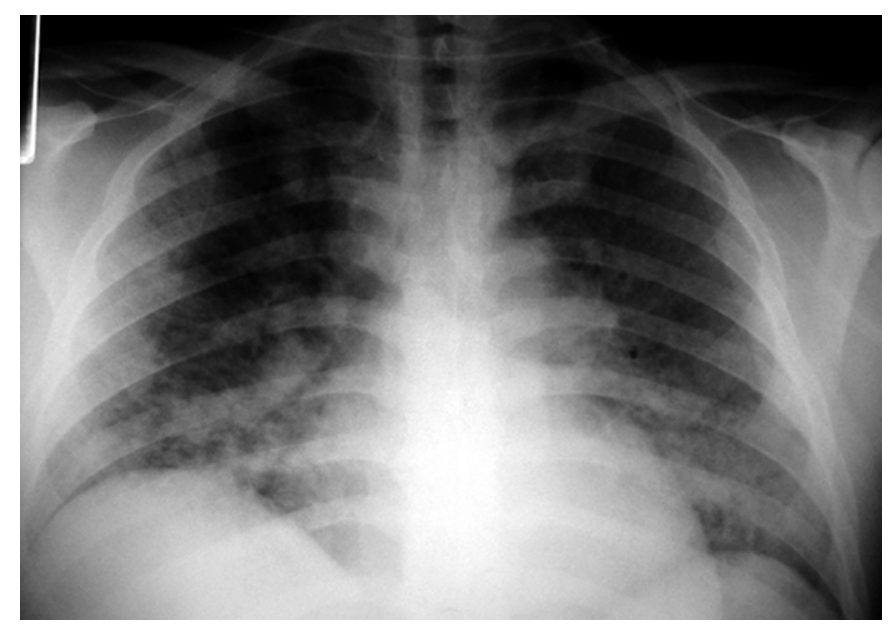

Fig. 2. Caso 4. Lesiones acinares coalescentes con broncograma de predominio basal. Pérdida de volumen bilateral. Condensación alveolar parcheada. 
tamaño entre 2 y $3 \mathrm{~mm}$, de predominio en campos medios en inferiores pulmonares. Pueden existir adenopatías perihiliares, como el paciente $n^{\circ} 1$, que no calcifican y son difíciles de objetivar radiológicamente por la contigüidad de las lesiones parenquimatosas $(5,6,8)$.

Ocasionalmente se presentan casos de neumonitis complicada, como nuestro paciente 3 , que o bien están ocasionados por el mismo virus $\mathrm{HZ}$, o por sobreinfección bacteriana. Si es neumonitis vírica, la patogénesis es por infección activa de las células epiteliales alveolares, y su presentación, secundaria a la viremia, es durante los tres primeros días de la aparición de la erupción, con un cuadro cínico-radiológico de neumonía por germen atípico. Por el contrario las neumonitis bacterianas son más tardías y tienden a formar focos de condensación y abscesos pulmonares $(9,10)$.

Por último es importante realizar un diagnóstico diferencial radiológico de los nódulos reticulonodulares difusos en pacientes febriles, ya que su etiología puede corresponder tanto a patología infecciosa (tbc, enfermedades micóticas, neumonitis vírica, parasitosis, sepsis por G-, toxoplasmosis.), como a cuadros de etiología no infecciosa (metástasis hematógenas) $(9,10)$.

\section{Bibliografía}

1. Moshen AH, McKendrik M. Varicella pneumonia in adults. Eur Respir J 2003; 21: 886-91

2. Golpe Gómez R, García Aranguena L, García Pérez MM, de la Roza Fernández CO, Fernández Rozas SM, et al. Varicella pneumonia in the previously health dult. An Med Interna (Madrid) 1999; 16: 83-6

3. De la Cruz Morón I, Alfageme Michavila I, Muñoz Lucena F, Ramos P, Rojas JL, García Polo C. Pneumonia due to varicella zoster virus in adult: a review of 13 cases. Arch Bronconeumol 1999; 35: 357-9.

4. Alemán Llanso C, García Quintana AM, Alegre Martín J, Recio iglesias J, Falco Ferrer V, Fernández de Sevilla Ribosa T. Varicella pneumonia in the adult. A review of 25 cases. Rev Clin Esp 1997; 197: 690-2.

5. Paytuby C, Negredo E, Ferrer S, Monmany J, Barrio JL. Varicella pneumonia in the adult. Study of 9 cases. An Med Interna (Madrid) 2001; 18: 312-6.
6. De la Pena L, Izaguirre D, Aguirrebengoa K, Grande C, Montejo M. Varicella pneumonia in the adult: study of 22 cases. Enferm Infecc Microbiol Clin 2000; 18: 493-5.

7. Rodríguez Borregán JC, Domínguez Artiga MJ, Minambres E, Tejerina Álvarez E, Holanda Pena MS, González Fernández C, et al. Varicella pneumonia in adults: 30 cases. An Med Interna (Madrid) 2003; 20: 6126.

8. Popara M, Pendle S, Sacks L, Smego RA Jr, Mer M. Varicella pneumonia in patients with HIV/AIDS. Int J Infect Dis 2002; 6: 6-8.

9. Umans U, Golding RP, Duraku S, Manoliu RA. Herpes simples virus I pneumonia: Convencional chest radiograph pattern. Eur Radiol 2001; 11: 990-4.

10. Aquino SL, Dunagan DP, Chiles C, Haponik EF. Herpes simples virus I pneumoniae patterns on CT scans and conventional chest radiographs. J Comput Assist Tomogr 22: 795-800. 